\title{
The Outsourced Chief Investment Officer Model of Management and the Principal-Agent Problem
}

\begin{abstract}
By convention, the responsibility for framing pension fund investment strategy lies with boards and their investment subcommittees, outsourcing the major part of the implementation of chosen investment strategies to various asset managers. In recent years, some pension funds have begun to outsource the investment strategy and implementation thereby locating authority and responsibility with external providers. In this paper, we focus upon the Outsourced Chief Investment Officer (OCIO) model of management emphasising the forces driving the adoption of this type of arrangement, its characteristics and what defines success. This model of management has the merit of replacing multiple providers with one contract on a fee-for-performance basis. For this model to be effective, it is shown that it must be well-governed. This includes clarity of mandate and delegation as noted in prior research on pension fund governance. In addition, any governance regime must address the principal-agent problem if the OCIO model is to realise clients' ambitions. This may require high-level Board competence, investment advisory services, and performance assessment processes that are sensitive to the unseen forces that influence success.
\end{abstract}

Keywords. Outsourced investment management, pension fund governance, principal-agent problem JEL Codes. G23, H26, R10

\section{Acknowledgements.}




\section{Introduction}

By convention, many pension funds manage the realisation of their investment goals and objectives by outsourcing the production of risk-adjusted returns by asset class and investment product. ${ }^{1}$ The hub-and-spokes model of governance and management is, in theory, an effective way of separating authority (board) and responsibility (intermediaries) for the production and coordination of the tasks and functions that make up the provision of pension benefits derived from the investment of accumulated funds. In this model of management, the board has oversight of those responsible for allocated tasks and functions using its authority to set the fund's strategic asset allocation, the standards of performance of its providers and switch mandates, as appropriate, between competing providers.

There are other ways of managing the production process including insourcing the investment of pension fund assets (Author and co-author 2 2017). Instead of managing providers through service contracts, set in accordance with industry norms and conventions, insourcing utilises an expanded executive staff with employment contracts whose terms and conditions reflect the goals and objectives of the organisation and the market premium available to those who have scarce skills and expertise. There may well be, in fact, a discount applied to any market premium if pension funds offer employment contracts with terms and conditions that favour collective interests over individual interests (Hart and Moore 2008). Disintermediation and re-intermediation are favoured strategies when a fund is of a certain size in assets under management (AUM) with concomitant

1\%. The term "convention" refers to the social practices of an industry (Brennan et al. 2013, 17, 20-21, 100102). Conventions can be distinguished from "norms" which refer to industry-wide expectations as to the proper nature and scope of behavior in an industry. Norms and conventions are created "when markets are thick-in the sense that many actors face similar challenges in their dealings and stand to benefit from concerted responses to them" (Gilson et al. 2013). 
capabilities and resources (see generally Teece et al. 1997). Size can also provide these organisations sufficient leverage to rewrite the terms and conditions of service and employment contracts.

Another model of pension fund governance and management has claimed attention: variously labelled, this model of management involves the outsourcing of the investment strategy and its implementation to another entity. The Outsourced Chief Investment Officer (OCIO) model of pension fund management locates the authority and responsibility for investment strategy with an external agent. This paper explains how and why the OCIO model has become important in the institutional investment industry. In doing so, we suggest that it is an organisational innovation driven, in part, by factors endogenous and exogenous to the conventional hub-and-spokes model of pension fund governance and management. We position this model with a set of other possible models, suggesting that it has certain advantages for smaller and mid-sized pension funds that do not have the options available to larger funds. At issue is how and why the OCIO model of management can meet the challenges facing asset owners and, in particular, pension funds over the coming decades.

In some jurisdictions, the $\mathrm{OCIO}$ model is also known as the Delegated $\mathrm{CIO}(\mathrm{DCIO})$ model whereas in other jurisdictions it is termed Fiduciary Management (FM). Whatever the label, it is a mode of management defined by its functions. For example, Van Nunen (2008, xii, 1-2) noted that these types of managers take responsibility for "comprehensive risk management, strategic decisionmaking, and effective organisational governance" while "overseeing a decentralised, outsourced array of investment managers". His approach is consistent with other functionalist accounts of the structure and organisation of the financial services industry (see Merton and Bodie 2005). The term OCIO management could be taken to mean that these types of arrangements necessarily include the transfer of legally enforceable obligations like the duty to act solely in the interests of pension plan participants from governing boards to third-party commercial entities. In later sections of the paper 
it is shown that, whatever the virtues of the OCIO model of management, there remain important governance issues to be resolved.

We begin by identifying the advantages of the conventional hub-and-spokes model of pension fund governance and management, and its place in investment theory and practice over the 1985-2005 period of strong global financial market performance. It is suggested that the search for alternative models of governance and management is due, in part, to the costs and consequences of market turmoil in the aftermath of the global financial crisis. The OCIO model is identified as one response to these pressures. An organising framework for evaluating the attractiveness of different models comes from the twelve principles of best-practice management (Author and co-author 3 2008). One key finding from this research is that notwithstanding the virtues of OCIO management, it is not simply an arm's length contract, it requires governance. Using the principal-agent model, this issue is explored in a later section of our paper demonstrating the crucial role that independent advice can play in realising the benefits of OCIO management.

Our paper brings to light principles and practices by eschewing the presentation of detailed information on the industry and its organizations in favour of the building blocks needed to understand recent developments in the industry. This approach is common in the social sciences, where in-depth knowledge of firms, industries and sectors is often translated into a logic that goes beyond the particularities of experience and fieldwork (see Helper 2000; Baker et al. 2001, 2002). More specifically, this paper builds upon Author and co-author 3's (2008) models of best practice pension fund governance, our work on the ways institutional investors responded to the onset of the global financial crisis (Author and co-author 3 2010), and work on the models of investment management (Author and co-author 2 2017). This research has been applied to other types of financial organisations including sovereign wealth funds, family offices and endowments, and national investment institutions (see Author, co-author 1 and co-author 2 2013). 


\section{Convention and Financial Markets}

We begin with the hub-and-spokes model of pension fund governance, a recognised organisational form, and use it as a benchmark in explaining how and why a rather different organisational form has gained traction in the industry. In doing so, it should be acknowledged that, at any point in time, in any industry there is considerable organisational diversity notwithstanding the apparent dominance of one or two organisational types (see Hannan and Freeman 1989). In principle, the status of one model versus another is owed, in part, to its efficacy in dealing with or adapting to past circumstances. However, any model of management can become so entrenched in customary practice that it becomes an impediment to adapting to changing circumstances (Gans 2016). It is arguable that this is precisely the problem facing the industry.

\section{Board authority and governance}

Pension funds and pension fund boards are similar to corporations in that funds are entitled, at their discretion, to own property and a wide variety of financial instruments. Pension fund boards use those property rights to frame and implement investment strategy in pursuit of an overarching goal to pay pension benefits. In many jurisdictions, pension fund board members are expected to have relevant skills and expertise and may be subject to similar legal rules and standards of behaviour applicable to corporate board members.

The hub-and-spokes model of investment management and governance is a bridge between the flexibility of a corporation and the fixed purpose of a pension fund. ${ }^{2}$ In this model, the board and its

\%. The demand for flexibility in the purchase and provision of financial services within and between relevant tasks and functions is one reason intermediation is so important in the global financial services industry. Other 
executive team use their authority as member representatives to frame and implement investment strategy ensuring that participants' interests are protected and commitments are honoured. When members' assets are placed with investment providers, funds do so to take advantage of the scope of the market for financial services and the flexibility of providers in adapting to changes in financial markets. By holding multiple service contracts according to asset class and investment style, it is presumed there is a premium to be had in switching assets between providers according to their relative performance. ${ }^{3}$ Given the skill and expertise necessary for designing an investment strategy and switching between providers, investment consultants have become integral to the investment management process (Author and co-author 2 2017).

\section{Market position and performance}

Pension fund governance and management in OECD countries came to maturity in a benign environment: notwithstanding a handful of standout events such as the Asian financial crisis of 1997 and the Long-Term Capital Management debacle in 1999, year-to-year stock market performance in London and New York was systematically positive over the period 1985-2007. The conventional model of pension fund governance and the standard recipe book were well rewarded (Ho and Lee 2004). Furthermore, investing at home was rewarded reinforcing investors' beliefs in the virtues of Western financial markets and light-touch government regulation (Barth et al. 2012). Indeed, as

accounts of intermediation in the industry emphasise the existence of information asymmetries (see, for example, Allen 1990; Allen and Santamero 1998).

3\%. In many jurisdictions, the default clause in investment management agreements allows both parties to terminate the agreement "at will" subject to an agreed notice period (e.g. 30 days) and the time taken to unwind commitments. It is believed in some quarters that the threat of termination is sufficient to ensure an alignment of interests between parties. Research suggests this option does not necessarily empower smalland medium-sized clients (Author and co-author 2 2017). 
each event was absorbed by developed financial markets confidence grew in the integrity of the received theory and practice of investment management (Shiller 2005). A predisposition in favour of the status quo and widespread belief in the power of mean reversion concealed the long-term costs and consequences of conventional ways of doing business for pension fund management.

Over the first decade of the $21^{\text {st }}$ century, market forces gathered momentum to shake confidence in the virtues of convention (see Lo 2012 with Fama 1970). Lost in the obsession of investors and the public alike with the upward trajectory of developed financial markets were the increasing costs associated with the secular decline in discount rates. As assumptions were slowly revised, renewed pressure was brought to bear on stock market investment strategies. At the same time, burgeoning growth in the financial markets of developing economies garnered increasing attention led, in part, by asset managers such as Goldman Sachs (Author 2014). Realising the potential of these markets prompted greater reliance by the average pension fund on large investment managers with global reach. Doubts have been raised about the goodness of fit between conventional ways of governing pension funds and $21^{\text {st }}$-century financial markets (Author and co-author 32010 ).

\section{Realising goals and objectives}

In this context, asset owners of various types including pension funds have come to recognise that there is a premium on adaptability and innovation, going beyond doing things better. Adaptability refers to adjusting investment strategies to changing expectations, distinguishing between isolated events and systemic shifts in market forces. Innovation refers to doing things differently, setting aside industry conventions in favour of new modes of organisation and management which are deemed more consistent emerging realities than past practices (Birkinshaw et al. 2008). Doing things better refers to reaping the benefits of the status quo and, where possible, adopting the principles and practices of best practice governance. By our account, the OCIO model is an instance of 
adaptability and innovation, transcending the temptation to simply doing things better (within the status quo).

In this regard, the OCIO model could combine the various tasks and functions that make-up the investment process such that many of the transaction costs apparent in the hub-and-spokes model are internalised and the benefits of teamwork and the coordination flow to the asset owner. Teamwork and coordination are especially important in contemporary global financial markets because of the (increasingly) diverse elements that make up the investment value chain and the domain-specific nature of investment skill and expertise (Author and co-author 2 2017). As we show, facilitating teamwork and coordination requires a form of organisation and a mode of contract able to reconcile the interests of asset owners and $\mathrm{OCIO}$ providers such that neither are held hostage to specialised providers and the resulting arrangements.

\section{Models of Governance and Management}

In order to appreciate the significance of the OCIO model, in this section we situate it in context - in relation to recent debate about the virtues or otherwise of insourcing as opposed to outsourcing and in relation to the key issues concerning the framing and implementation of investment strategy. There are various ways of representing investment strategy focusing, for example, on quantitative as opposed to qualitative modes of management (see Litterman 2004) and strategic asset allocation (see Campbell and Viceira 2002). There are limits to what can be presented in any academic paper; these types of issues - significant as they are - are left to another time.

\section{Insource or outsource}

The term 'strategy' is used to refer to the norms and conventions guiding the allocation of investable assets to asset classes and return drivers. These types of investment decisions normally derive from a strategic framework and/or intended investment direction that involves certain higher level 
considerations. For example, the significance and meaning attributed to risk; the appropriate amount of risk to take given the fund's goals and objectives; how to integrate different time horizons and preserve intergenerational equity; and, the fund's wider responsibilities to stakeholders. To date, most funds rely upon their boards to set the strategic framework while the executive team provides technical support for the implementation of these decisions.

By convention, pension funds decide whether to hold internally (insource) the tasks and functions necessary to realise a target risk-adjusted rate of return or go to the market for (outsource) those tasks and functions. Where there is a high degree of complementarity between tasks and functions, the effective orchestration of the production process is fundamental to realising an organisation's over-arching risk and return objectives. Here, the management issue is whether the costs and benefits of segmenting tasks and functions by asset class (for example) and having them provided through external agents outweigh the costs and benefits of managing each element internally via an integrated management process. The basic thesis of this paper is that the conventional hub-andspokes model of management suffers from weak delegation (control and coordination), given the OCIO alternative.

\section{Economies of scale and scope}

There are significant economies of scale within the global financial services industry evident, for example, in the success of bulge-bracket asset managers. Economies of scale have two dimensions. First, there are the upfront costs involved in establishing the management systems and infrastructure necessary to allocate inflows and outflows of financial assets. Maintaining the integrity and the efficacy of such systems requires continual upgrading and investment. Spreading the costs of these systems is an essential ingredient in minimising the unit costs of investment management. Second, the asset management process is labour-intensive, requiring domain-specific skills and expertise that are widely referred to as intellectual property but are more accurately a 
form of intellectual capital. Setup costs are significant, but once established portfolio teams can absorb large volumes of assets and thereby pay a premium for the most talented professionals (Author 2016).

Economies of scope are also important, but are more nuanced in effect. Large asset managers often proclaim the virtue of having available a wide variety of investment services (Author 2002). Going to market for each task and function can incur significant transaction costs, including the time taken to search and assess competing service providers (see generally Caplin and Martin 2011). Furthermore, given the importance of orchestrating complementary tasks and functions for the production of riskadjusted returns, segmentation of the investment process can impose significant costs on an otherwise well-conceived investment strategy. Notwithstanding the supposed virtues of separate contracts for service providers, pension funds can find it difficult to orchestrate in a timely fashion the implementation and management of investment.

\section{Four ideal types}

In what follows, we assume that the options facing the sponsor of a pension fund in responding to the apparent shortcomings of the conventional model of pension fund governance and management have two dimensions. For larger funds with a volume of financial assets consistent with insourcing the production of investment returns, the implementation of a chosen investment strategy framework or strategy can be via insourcing or outsourcing or a combination of both. Smaller funds might also consider insourcing some tasks and functions, while recognising that there will be tasks and functions where the volume of assets is not sufficient to provide internally those activities in a cost-efficient manner. Then there are small funds where insourcing is simply not possible. 
Figure 1. Models of Management (A)

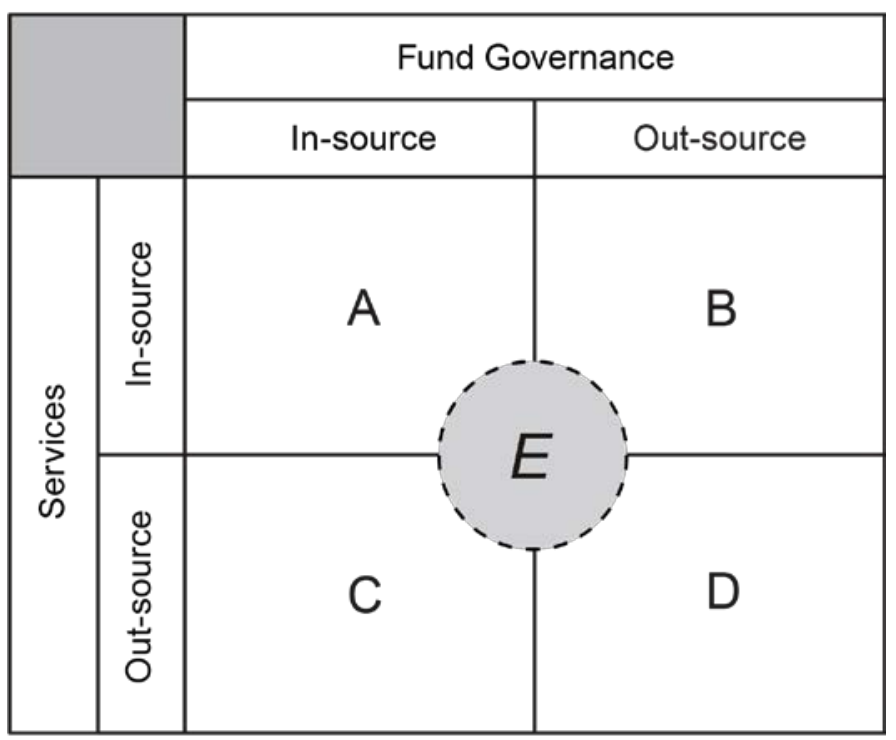

Source: Author

These cases, and others, are represented in Figure 1. All models have some part of the governance function insourced. We assume that the Board remains the owner of the decision with respect to the high-level beliefs, mission/goals/benchmarks and governance policy and the strategic framework.

- Model A (Fully insourced) is the larger fund referenced above. It combines a well-resourced governance function which frames the investment strategy with the insourcing of the tasks and functions (services) needed to realise that strategy.

- Model C (Insourced $\mathrm{ClO}$ ) is the conventional hub-and-spokes model where the board, its subcommittees, $\mathrm{ClO}$ and executive team and advisors frame investment strategy and outsource its implementation. ${ }^{4}$

5 . Consultants can play a significant role in this type of organisational form, not only advising on issues related to implementation but also in orchestrating the process whereby the domain-specific skills and expertise of 
- Model B (Outsourced strategy, Insourced implementation) is unusual in that the governance function is outsourced but implementation is insourced. This model has been observed in asset management company settings where it is expected that the governance function should be independent of the sponsoring company. In effect, this model of management presupposes that there can be significant conflicts of interest when senior executives dominate the governance of its 'captive' pension fund. At the same time, insourcing implementation can be cost-efficient, reinforced by an alignment of interests otherwise not possible when service provision is outsourced.

- In Model D (Outsourced $\mathrm{ClO}$ ), the strategic function is outsourced along with the implementation of the chosen investment strategy. Depending upon the jurisdiction, the entity responsible for framing and implementing investment strategy is, quite literally, the fiduciary being subject to common law and statute-based standards of behaviour that are consistent with fiduciary duty. In most jurisdictions, both the client and the OCIO manager are subject to fiduciary duty in that the client is required to oversee the OCIO manager in a manner consistent with trust law. This is certainly the case in the US, UK and the Netherlands.

- Notice that there may be a space or set of activities which are not entirely consistent with the particularities of each model. This is represented in Figure 1 by the middle space E. For 
example, a Model A organisation could outsource some activities just as the Model D organisation could insource some activities. ${ }^{5}$

OCIO managers come in various forms. Some companies specialise in OCIO management, being stand-alone organisations that have the skills and expertise needed to frame and implement investment strategy. In other cases, large multifunctional financial service companies provide OCIO management as a service along with a wide range of banking and investment services. Yet other companies have entered the market for OCIO management from the consulting side of the asset management industry, deploying skills and expertise normally offered to Model A and Model C types of pension funds. In many cases, specialist OCIO management companies and asset consulting companies rely upon outside managers when implementing investment strategy. By contrast, large financial companies use in-house portfolio management subject to market standards.

Specialist OCIO management companies may excel at the framing of investment strategy but face significant transaction costs when searching for, evaluating, and managing service providers essential to the implementation of strategy. In this respect, they may rely upon asset consultants to cut through the maze of market claims and counterclaims. Asset consultants are skilled at framing investment strategy and have at their fingertips extensive knowledge of the market for financial services. They also have significant experience with the management and control of the flows of funds between different activities and the investment services associated with liability driven

$5 /$ Large, multifunctional organisations can find it difficult to remain at the leading edge of innovation in any sector or industry. As such, outsourcing can provide an action space for the senior executives of large financial institutions (asset owners and asset managers) seeking to adapt to, or keep abreast with, new ideas and tactics in the industry. If successful, outsourcing can become insourcing as new initiatives are integrated into the business of the financial institution (Bachher and Monk 2013). 
investing (LDI). However, when it comes to orchestrating the investment process, their capacity to do so can be constrained by their limited experience with the implementation of strategy and accountability for performance. In many cases, asset managers have the full-service capabilities for OCIO mandates and are used to accountability for performance. But they have limited experience with accountability for balanced sheet outcomes and with the Board interface.

\section{Principles and Practices}

In this section, we distil lessons learned from our research on the logic and performance of the OCIO model through six organising principles. At one level, these principles are specific to the OCIO model. However, we show that these principles map onto our previous findings as regards the principles and practices of best practice pension fund governance (see Author and co-author 3

2008). Recall that our previous research was based upon a theoretical framework informed by academic research plus deep experience in the sector. As in this paper, we also have the advantage of international experience across the sector in public and private large and small investment institutions.

In Author and co-author 3 (2008), 12 principles of best practice pension fund governance were identified noting that the size of an organisation, the legal form of an organisation, and the relative status of expertise and representation often mean that "core best practice factors" tend to be found in certain types of pension funds whereas core factors plus "exceptional factors" are only found in a select group of pension institutions. In our research, it was found that best practice $\mathrm{OCIO}$ institutions tend to be those that join core factors with exceptional factors. This is because higherperforming funds characterised by "exceptional" governance practices are also those funds more able to innovate and adapt their governance practices to changing circumstances-going beyond doing it better within the conventional model of fund management. This is one reason why the 
OCIO model has been recognised as innovative and the industry and why implementation of the model can be challenging.

OCIO principles of best practice

Immediately below, we identify the six principles of OCIO best practice ignoring, for the moment, broader issues of governance and oversight. These are listed one through six, and are mapped onto Author and co-author 3 (2008) exceptional factors of pension fund governance. ${ }^{6}$

OCIO Principle 1: the use of a highly competent investment team tasked with clearly specified responsibilities and mandate, with direct accountabilities to the Board Author and co-author 32008 Factor 7]. Essential to a well-functioning OCIO management program is a clear mandate along with well-defined measures of performance. Most obviously, this can include investment return, risk, and performance objectives set in relation to the broader objectives of the client. So, for example, the long-term objective of the client could be to ensure solvency of the pension fund in relation to its obligations to participants. A subsidiary goal could be to limit calls for more resources from the client or sponsor over the longer term.

Translating the mandate into performance measures is an essential ingredient in providing the OCIO manager with an unambiguous focus. It is a truism that organisations manage what is measured (Lowenstein 1996). This is important both for the client and for the OCIO manager. For the client, accepted performance measures provide a means of testing the effectiveness of the provider. For

$\%$. There are limits to the implementation of best practice given the heritage of an institution and its ongoing commitments (Gertler 2001). The legal environment in which a financial institution operates normally frames contractual arrangements, thereby excluding options otherwise thought desirable (La Porta et al. 1998). 
the OCIO manager, such measures can be used to impose discipline upon the activities of its own organisation. ${ }^{7}$ Both elements are fundamental to ensuring a well-functioning relationship.

OCIO Principle 2: effective incentives and compensation practices used to align actions to the mission, delegations being best assessed by reference to key performance indicators tied to inputs and outcomes [Author and co-author 32008 Factor 9]. OCIO management is notionally a long-term commitment by both the client and the provider and considerable attention is needed to reduce any misalignments in the role. Given objectives and performance measures, the client has an interest in ensuring that the provider shares in both the upside and downside of the investment programme. This is one way of reinforcing the link between the framing of investment strategy and its implementation, providing the $\mathrm{OCIO}$ manager with a strong incentive to integrate the investment process with client objectives.

Notice, too large a payment for performance is problematic as it can introduce short-term noise into fees and produce undue rough justice. Incentives are best when including fixed elements (supporting OCIO overheads) and variable elements tied to inputs to the OCIO process and service.

OCIO Principle 3: selection to the board is ideally guided by numeric skills, capacity for logical thinking, ability to think about risk in the probability domain; boards that make up for any deficits in these skills through specialised subcommittees or specialised independent advisers [Author and coauthor 2008 Factor 8]. By convention, the board with investment committee input has final authority over the investment framework, investment strategy and its implementation. OCIO

\footnotetext{
$7 /$ While specificity is a virtue, clients may also seek performance measures that allow for comparison across providers of OCIO management services. Inevitably, a well-functioning market for financial services thrives when comparability is one element of the process of assessing competing providers.
} 
management involves the formal delegation for these matters to an external agent. In these circumstances, delegation requires deference to the agent's judgement. To second-guess an agent would be to discount the value of $\mathrm{OCIO}$ management and put-in-play the contract setting out the terms and conditions of the agreement binding the parties together.

The over-riding issue here is whether the board has sufficient understanding of their agent's work so as to challenge the investment strategy and its implementation and the agent's suitability in the OCIO role. These are tests that the board should make of any delegated agent - internal or external. Ideally, boards should have the domain knowledge and numeric and probability skills required to make these challenges. Where this is not the case, and commonly it is not, there are two instances where this critical oversight can be effective: where investment subcommittees claim a measure of investment insight by virtue of the skills and expertise of subcommittee members (Author 2007); or where an independent adviser completely separate from the OCIO brings these insights to bear and acts as trusted adviser (but not as a source of second-guessing). One or other of these governance constructs is critical to the OCIO success.

OCIO Principle 4: Frame the investment philosophy and process by reference to the institution's comparative advantages and disadvantages [Author and co-author 32008 Factor 10]. One of the most important benefits of $\mathrm{OCIO}$ management is the opportunity to garner the benefits of complementarity, having direct control over each element in the chain of investment services through the integration of investment strategy and its implementation. This is a key test of the efficacy of any OCIO management relationship. This can involve, for example, adopting a one-fund investment approach wherein the allocation of assets to portfolio managers is considered on an integrated basis along with the ongoing 'contest for capital'. 
Ultimately, the success of OCIO management depends upon the integration of best-in-class services otherwise separately provided in the hub-and-spoke model. This reduces the attractiveness of an OCIO arrangement that favours 'in-house' products without a value-based assessment of those services against best-in-class criteria. In-house arrangements are sometimes used to mitigate the overall fee. Even so, the inability to separate the costs and benefits of services can weaken the attraction of the model.

OCIO Principle 5: utilise decision-making systems that function in real-time rather than the formal timetable of consultations and meetings and in particular give transparent decision rights to the $\mathrm{ClO}$ and executive team so as to facilitate decisions and actions [Author and co-author 32008 Factor 11]. To realise the goals and objectives of a fiduciary mandate, and reap the benefits of greater coordination over complementary activities, being able to act within the terms and conditions of the agreement without negotiation is a key ingredient of success. This requires transparency as to the decision rights of the OCIO manager in relation to the client, and transparency within the manager as to the allocation of responsibilities for performance of the agreement. Lack of transparency on both counts is likely to discount the benefits of outsourcing the framing and implementation of investment strategy.

OCIO Principle 6: sustain a learning culture and adaptive model of management which deliberately encourages change, and challenges the commonplace assumptions of the industry [Author and coauthor 32008 Factor 12]. Another test of the efficacy of any OCIO management relationship is the 'culture' of the provider and in particular itsr adaptive capacity in relation to financial market risk and uncertainty. At one level, adaptive capacity can be measured by the responsiveness of the OCIO manager to shifts in market expectations being both a strategic issue and an issue of orchestrating the investment process. At another level, it reflects the alignment (or not) of managers' risk budgets with their governance budgets. Elsewhere, we provide a detailed formulation linking conceptually 
and practically risk budgets with governance budgets (Author and co-author 3 2008). OCIO arrangements should be accountable for significant failures in their performance such that it is possible to terminate and replace providers.

\section{Implementation of OCIO best practice}

Whereas the hub-and-spokes model governs the investment process through organizational oversight, deliberation, and decision-making, OCIO management would replace it by a single or a small set of contracts for services. The means by which the parties to the agreement realise their common objectives is through the combination of a well-defined set of goals and objectives, agreed measures of performance, and transparent decision-rights and delegation with deference subject to critical oversights. In this sense, contract stands as a blueprint for action by the party charged with responsibility for framing and implementing investment strategy (Davis 2013). Here, however, is an issue which goes to the heart of the contractual agreement binding the parties together: whether contracts for services are complete in terms of being a full specification of the privileges and responsibilities of both parties (Argyres et al. 2007).

If an OCIO manager is to claim deference for its decision-making, being adaptive and responsive to shifts in market expectations rather than hemmed in by convention, any contract for services needs to be sufficiently flexible such that it facilitates the best endeavours of the manager (Schepker et al. 2014). Put slightly differently, to the extent checks and balances exist in the relationship between the parties, the OCIO manager requires a degree of certainty about the scope of its authority and responsibilities so as to realise the potential inherent in the outsourcing of investment strategy and its implementation. For some, this is an issue of trust (Connelly et al. 2012): the degree to which a client willingly defers to the provider in terms of its chosen strategies and actions taken albeit subject to measures of performance against goals and objectives. 
Note, however, in many cases trust is earned rather than assumed from the start of a relationship. Three implications follow. First, a pension fund board may find it difficult in the early stages of its relationship with an OCIO manager to have a degree of trust consistent with the flexibility desired by both parties. As such, the initial contract binding the parties together may contain reporting protocols that mimic conventional investment management agreements. Second, as the client becomes more comfortable with the manager and the discretion inherent in the relationship, the contract may evolve to be more flexible and open-ended than a standard investment management agreement (Mayer and Argyres 2004). Third, over time, the contract may recede into the background and be replaced by an ongoing relationship between the parties. In this respect, rather than defining the relationship between the parties, contract would then become a tool of last resort.

\section{The Principal-Agent Problem}

The efficacy of OCIO management depends, as in other economic relationships, upon the degree to which sponsor or pension fund (principal) is an effective client and the OCIO manager (agent) is an efficient provider. In economics, the principal-agent problem exists in any situation where an entity "delegates an action to an agent" (Laffont and Martimort 2002, 14). Given the significance of delegation in modern economies, and the importance of this issue for the effectiveness of OCIO management relationships, in this section we discuss three aspects of the problem as well as the various mechanisms used to manage the issue. Some types of OCIO management relationships are more vulnerable to the principal-agent problem than other types.

\section{Identity and responsibility}

The principal-agent problem is deeply embedded in the global financial services industry (Ambachtsheer 2016). Consider, for example, the links in the investment chain connecting the pension fund participant with, in order, the pension fund, the actuary, the asset consultant, the custodian, the asset manager, and the accountant (Black 1992). Each link in the chain is formally 
constituted through a contract binding the parties together wherein each party has the rights and privileges of a person but is, normally, an organisation not a person per se. The employee representing an organisation directs other employees in the fulfilment of the contract and other contracts with similar organisations. Normally, contracts between organisations are mute as regards intra-organisational matters.

Pension funds reliant upon the hub-and-spokes model of investment management often seek to understand how an asset manager is internally resourced and organised for the realisation of a target risk-adjusted rate of return (Urwin 1991). This is because of their vulnerability to failures of management in such organisations and the potential contribution that the asset manager's skill and expertise is crucial to realising goals and objectives. Compared to the hub-and-spokes model of management, OClO management is a effective way of mapping-out the roles of the client and agent, where the former is responsible for selecting the OCIO manager and the latter is responsible for all matters pertaining to the framing of investment strategy and its implementation. With clarity of mandate, simplicity of performance measures, and the alignment of interests the client need not intrude upon the investment management process and the performance of each element in the process. The OCIO model presupposes that the agent bears the costs and consequences of the investment management process.

\section{Two institutional factors}

There is a marked difference between clients and their agents in terms of their organisational longevity or persistence. It is expected that pension funds persist as long as their obligations and commitments, with a long-term planning horizon consistent with participants' retirement plans. In many jurisdictions, pension funds have an organisational form which is protected in statute. By contrast, there is an active market for corporate control in the global financial services industry. Any deal struck between a principal and its OCIO manager must be robust enough to outlast those 
responsible for negotiating the deal. At the same time, recognising that both the agent and its employees may come and go over the course of an agreement, pension funds may well seek a contract which provides for termination should such changes impose undue costs on the client.

It should also be recognised that principals and agents are not the only players in these relationships. As noted above, the hub-and-spokes model of investment management comes with a string of intermediaries including expert advisors and consultants. Whereas Judge $(2013,2015)$ disparages agents, arguing they impose transactions costs and greater complexity in the production of financial services, these agents are often fundamental in the framing and realising of goals and objectives. Furthermore, advisors and consultants can provide a degree of continuity in commercial relationships otherwise subject to the flux and flow of the financial services industry. In what follows, we suggest advisors and consultants may play a key role in providing the expertise necessary for the effective governance of the principal-agent problem.

\section{Governing OCIO management}

Economic theorists suppose that the fundamental problem affecting the relationships between principals and agents is the fact that information is not evenly distributed between the parties (Meckling and Jensen 1976). Because the agent is responsible for the framing of investment strategy and its implementation, it has access to information that the clients cannot directly observe. As such, it can systematically limit the distribution of relevant information such that the principal is at a disadvantage. There are two possible effects of information asymmetry: adverse selection ("hidden knowledge") and moral hazard ("hidden action") (Laffont and Martimort 2002, 3). 
The standard principal-agent model assumes that information is scarce and the costs of developing information are significant. ${ }^{8}$ Assuming all organisations, in particular smaller pension funds, face significant budget constraints, it may be impossible for clients to overcome this disadvantage. However, it is reasonable to suppose that whatever the premium on information one of the defining characteristics of the global financial services industry is the volume of information available to third parties, whatever their standing in the investment management process. While we should take care not to confuse quantity with quality, the world envisaged by economic theorists has changed markedly over the past 50 years and will continue to do so with the advent of "big data".

Access to information is fundamental to the principal-agent problem (Aghion and Tirole 1998; Pratt and Zeckhauser 1985). A second element is the expertise and understanding available to the principal in overseeing its relationship with providers. ${ }^{9}$ A high level of expertise matching the expertise of the agent may empower the client to actively govern its contractual relationship, thereby dampening the costs and consequences of information asymmetry. Conversely, a low level of expertise relative to the agent may mean that the principal has limited capacity to assess the

$8 \%$. The costs and social consequences of the asymmetrical distribution of information have a long history in economics and the social sciences. See Akerlof (1970) for his seminal treatment of the issue, using a simple example to illustrate how a buyer can be at a disadvantage relative to a seller when assessing the quality of a product. Spence (1976) took the issue further, providing a systematic way of integrating the distribution of information with market phenomena.

$\%$ For Glode et al. $(2012,1724)$, expertise is required to process "information about the values of assets traded." They go on to suggest that "financial expertise...is the ability to acquire more accurate information." Thereafter, they observe that complex financial products require a level of expertise that is not readily available in the market, on a piece by piece basis. 
agent's investment management process. A lack of, or indeed systematic exclusion from, relevant information is likely to accentuate the problems associated with low levels of expertise. In these circumstances, the contractual relationship between the principal and agent is likely to continue until it fails (in dramatic fashion).

Figure 2. Models of Management (B)

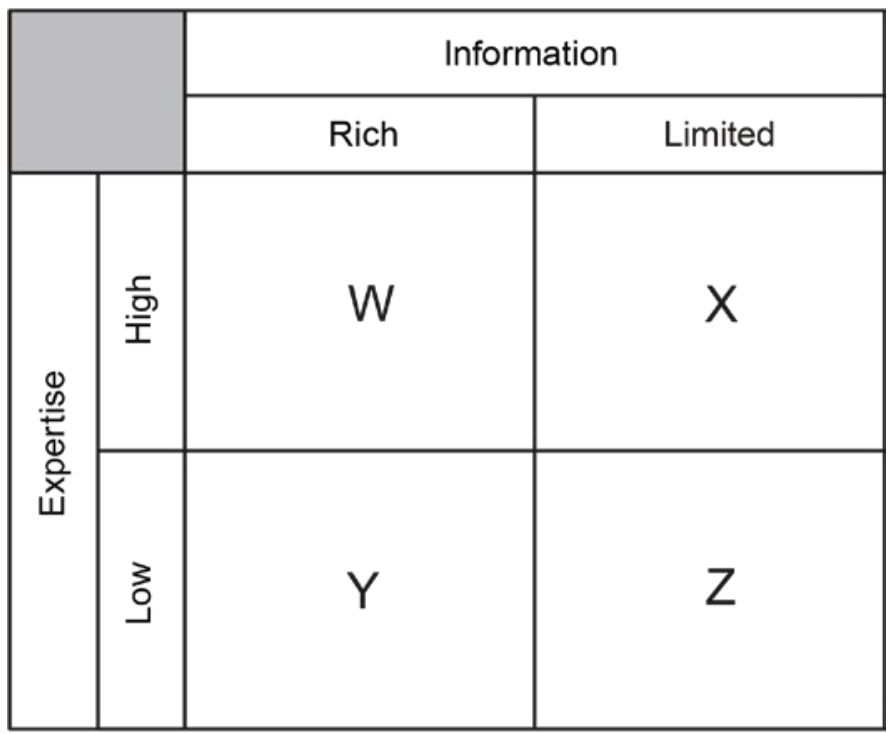

Source: Author

In these ways, the principal-agent problem has two dimensions and a set of possible states. In Figure 2, we provide a systematic mapping of the principal-agent problem relevant to governing OCIO management. Going beyond the standard way of representing the principal-agent problem, the issue is framed by reference to information and expertise with four ideal types. Our map of the principal-agent problem is rather abstract, suggesting the existence of categorically different types where, in fact, there is likely to be a continuum along the two dimensions of the problem.

- Model W represents the best possible situation for a principal governing an agent. A high level of expertise combined with information is likely to empower a pension fund client in relation to its OCIO manager. How is this possible? A client could employ a knowledgeable 
consultant or set of consultants, and it could hire key employees that have worked on both sides of the market.

- By contrast, Model $\mathrm{Z}$ is an instance where the client is captured by the OCIO manager, there being no basis for systematically overseeing its organisational robustness or its short-term and long-term performance. Either expert advice is not available at a fee which the fund can afford, and/or the provider systematically excludes the client from information and insight as to its strategy and implementation.

- Model $\mathrm{X}$ is entirely possible in that a high level of expertise notwithstanding limited information can empower a client to be an effective governing party if done on a strategic basis with selective expenditure on needed information. Here, a consultant with experience in this segment of the market could compensate for limited information by drawing upon information from other sources. ${ }^{10}$

- By contrast, Model Y would seem to be a losing proposition in that, notwithstanding a rich source of information, the principal simply does not have, or cannot afford, the expertise to take advantage of the available information in governing its relationship with the OCIO manager.

10\% Standard treatments of the principal-agent problem make little allowance for the systematic 'leakage' of information from agents to principals through repeated engagement and observation of the behavior of other similarly-placed parties. It has also been shown that the interaction between agents, between agents and principals, and between principals promotes the disclosure of information which, in a settled market, would otherwise be more 'sticky' than observed. See Caplin and Leahy (1994) on the release of information to the market. 
In the world observed, there are few Model $W$ cases, many Model $X$ cases, an increasing number of Model Y cases, but fewer Model Z cases. Those pension funds conscious of their reliance upon their OCIO manager, and sensitive to shifts and changes in the global financial services industry affecting the ownership and organisation of service companies, have begun to invest in expertise so as to discount the risks associated with adverse selection and moral hazard.

\section{Implications and Conclusions}

In this paper, we compared the OCIO model and its characteristics with the dominant hub-andspokes model of pension fund governance and management. At base, it involves outsourcing both the investment strategy and its implementation. Given the economies of size and scope that dominate the financial services industry, many smaller pension funds have identified OCIO management as a viable alternative to the conventional hub-and-spokes model. In Figure 1, other kinds of responses were identified including full insourcing by retaining responsibility for the investment strategy and the insourcing of its implementation. This type of response involves disintermediation and, in some circumstances, strategic re-intermediation (Author and co-author 2 2017). Our framework also includes a less familiar case where large financial institutions and corporations outsource the framing of investment strategy but insource its implementation.

The obvious other alternative to the traditional model is the insourcing of strategy via the insourced Chief Investment Officer (ICIO) while outsourcing implementation. The analysis that followed for the outsourced $\mathrm{ClO}$ was consistent with that for the insourced equivalent (ICIO) but with certain adjustments on the principal and agent issues. Internalising functions reduces but does not eliminate the principal agent issue. This relative advantage in improved alignment has a potential cost in terms of the reduced flexibility to replace the $\mathrm{ClO}$ and executive team. 
A key finding of our research is that the plan sponsor-OCIO manager relationship must be managed. Yet, the nature of this relationship is such that the modes of monitoring and oversight typical of the hub-and-spokes model are only partially relevant. We provide a set of principles and practices that underpin an effective plan sponsor-OCIO manager relationship that are linked to the previous research on best practice pension fund governance (Author and co-author 3 2008). Clarity of mandate and delegation with deference resonate with our template. It was also suggested that, in governing the plan sponsor-OCIO manager relationship, a key measure of success is being able to reap the benefits of complementary and the adaptive capacity of the manager.

Inevitably, any such service is formalised through contract. It was noted, however, that smaller pension funds contemplating a relationship with an OCIO manager face the prospect of being offered a standard contract on a take-it-or-leave-it basis. Larger clients can, of course, claim special treatment because of their significance to providers. Both sides of the relationship may find virtue in a standard contract, particularly in the early phases of a relationship where trust is yet to be established.

This is the realm of the principal-agent problem. The apparent asymmetries in the relationships between many board and their OCIO managers are such that the former may bear the costs of adverse selection and moral hazard. The principal way to address the issue is through investment subcommittees with highly investment proficient members or with independent investment advice to the Board. It is shown that a well-informed expert client can be an effective partner in a plan sponsor-OCIO manager relationship. A less well-informed client without adequate information could well be exploited by a service provider.

Many of the current difficulties in pension fund investing and institutional asset management are derived from poor levels of governance. As much of this situation stems from the limited scale of 
many funds, the $\mathrm{OCIO}$ arrangements will no doubt be seen as an attractive way of addressing this issue. If OCIO arrangements can solve their own group of governance issues they can have a successful and lasting impact.

\section{Bibliography}

Aghion, P., and Tirole, J. "Formal and real authority in organizations." Journal of Political Economy, Vol. 105, No. 1 (1997), pp. 1-29.

Akerlof, G.A. "The market for "lemons": quality uncertainty and the market mechanism." Quarterly Journal of Economics, Vol. 84, No.3 (1970), pp. 488-500.

Allen, F. "The market for information and the origin of financial intermediation." Journal of Financial Intermediation Vol. 1, No. 1 (1990), pp. 3-30.

Allen, F., and Santamero, A. "The theory of financial intermediation." Journal of Banking and Finance Vol. 21, No. 11-12 (1997) pp, 1461-1485.

Ambachtsheer, K.P. The Future of Pension Management: Integration Design, Governance, and Investing. Hoboken NJ: John Wiley and Sons, 2016.

Argyres, N.S., Bercovitz, J., and Mayer, K.J. "Complementarity and evolution of contractual provisions: an empirical study of IT services contracts." Organization Science Vol. 18, No. 1 (2007), pp. 3-19.

Bachher, J.S. and Monk, A.H.B. "Platforms and vehicles for institutional co-investing." Rotman International Journal of Pension Management Vol 6, No. 1 (2013), pp. 64-71.

Baker, G., Gibbons, R., and Murphy, K.J. "Bringing the market inside the firm." American Economic Review Vol. 91, No. 2 (2001), pp. 212-218.

Baker, G., Gibbons, R., and Murphy, K.J. "Relational contracts and the theory of the firm." Quarterly Journal of Economics Vol. 117, No. 1 (2002), pp. 39-84. 
Barth, J.R., Caprio, G., and Levine, R. Guardians of Finance: Making Regulators Work for Us. Cambridge, MA: MIT Press, 2012.

Birkinshaw, J., Hamel, G., and Mol, M.J. "Management innovation." Academy of Management Review Vol. 33, No. 4 (2008), pp. 825-45.

Black, B. "Agents watching agents: The promise of institutional investor voice." UCLA Law Review Vol. 39, No. 4 (1992), pp. 811-893.

Brennan, G., Eriksson, L., Goodin, R.E., and Southwood, N. Explaining Norms. Cambridge: Cambridge University Press, 2014.

Campbell, J.Y., and Viceira, L.M. Strategic Asset Allocation: Portfolio Choice for Long-Term Investors. Oxford: Oxford University Press, 2002.

Caplin, A., and Leahy, J. "Business as usual, market crashed, and wisdom after the fact." American Economic Review Vol. 84, No. 3 (1994), pp. 548-65.

Caplin, A., and Martin, D. "Search and satisficing." American Economic Review Vol. 101 No. 7 (2011), pp. 2899-2922.

Davis, K.E. “Contracts as technology.” New York University Law Review Vol. 88, No. 1 (2013), pp. 83127.

Gans, J. The Disruption Dilemma. Cambridge MA: MIT Press, 2016.

Gertler, M.S. "Best practice? Geography, learning and the institutional limits to strong convergence." Journal of Economic Geography Vol. 1, No. 1 (2001), pp. 5-36.

Gilson, R., Sabel, C., and Scott, R. E. "Contract and innovation: The limited role of generalist courts in the evolution of novel contractual forms." New York University Law Review Vol. 88, No. 1 (2103), pp. $170-215$. 
Glode, V., Green, R. C., and Lowery, R. "Financial expertise as an arms race." Journal of Finance Vol. 67, No. 5 (2012), pp. 1723-1759.

Haldane, A., and May, R. "Systemic risk in banking systems." Nature Vol. 469, No.7330 (2011), pp. $351-55$

Hannan, M. T., and Freeman, J. Organizational Ecology. Cambridge, MA: Harvard University Press, 1989.

Hart, O., and Moore, J. “Contracts as reference points.” Quarterly Journal of Economics Vol. 123, No. 1 (2008), pp. 1-48.

Helper, S. "Economists and field research: you can observe a lot just by watching." American Economic Review Vol. 90, No. 2 (2000), pp. 228-232.

Ho, T.S.Y., and Lee, S.B. The Oxford Guide to Financial Modelling: Applications for Capital Markets, Corporate Finance, Risk Management, and Financial Institutions. Oxford: Oxford University Press, 2004.

Holmstrom, B., and Milgrom, P. "Multitask principal-agent analyses: incentive contracts, asset ownership, and job design." Journal of Law, Economics, and Organizations Vol. 7, No. 1 (1991), pp. $24-52$

Judge, K. “Fee effects." lowa Law Review Vol. 98, No. 4 (2013), pp. 1517-74.

Judge, K. "Intermediary influence." University of Chicago Law Review Vol. 82, No. 2 (2015), pp. 573642.

Laffont, J-J., and Martimort, D. The Theory of Incentives: The Principal Agent Model. Princeton: Princeton University Press, 2002.

La Porta, R., Lopez-de-Silanes, F., Shleifer, A., and Vishny, R.W. "Law and finance." Journal of Political Economy Vol. 106, No. 6 (1998), pp. 1113-55.

Litterman, B. Modern Investment Management. New York: John Wiley, 2004. 
Lo, A. "Adaptive markets and the new world order." Financial Analysts Journal Vol. 68, No. 2 (2012), pp. 18-29.

Lowenstein, L. "Financial transparency and corporate governance: you manage what you measure." Columbia Law Review Vol. 96, No. 5 (1996), pp. 1335-1362.

Malkiel, B.G., and Fama, E.F. "Efficient capital markets: A review of theory and empirical work." Journal of Finance Vol. 25. No. 2 (1970), pp. 383-417

Mayer, K.J., and Argyres, A.S. "Learning to contract: evidence from the personal computer industry." Organization Science Vol. 15, No. 4 (2004), pp. 394-410.

Meckling, W.H., and Jensen, M.J. "Theory of the firm: managerial behavior, agency costs and ownership structure." Journal of Financial Economics Vol. 3, No. 4 (1976), pp. 305-360.

Merton, R.C., and Bodie, Z. "The design of financial systems: towards a synthesis of function and structure." Journal of Investment Management Vol. 3, No. 1 (2004), pp. 1-23.

Pratt, J., and Zeckhauser, R. (Eds). Principals and Agents: The Structure of Business. Boston: Harvard Business School Press, 1985.

Schepker, D.J., Oh, W-Y., Martynov, A., and Poppo, L. "The many futures of contracts: moving beyond structure and safeguarding to coordination and adaptation." Journal of Management Vol. 40, No. 1 (2013), pp. 193-225.

Shiller, R.J. Irrational Exuberance. 2nd Edition. Princeton, NJ: Princeton University Press, 2005.

Spence, A.M. "Symposium: the economics of information." Quarterly Journal of Economics Vol. 90, (1976), pp. 591-597.

Teece, D.J. "Expert talent and the design of (professional services) firms." Industrial and Corporate Change Vol. 12, No. 4 (2003), pp. 895-916.

Teece, D.J., Pisano, G., and Shuen, A. "Dynamic capabilities and strategic management." Strategic Management Journal Vol. 18, No. 7 (1997), pp. 509-533. 
Towers Watson. Stronger Investment Theory and Practice. London: Thinking Ahead Institute, 2015.

Urwin, R. Defining and exploiting investment manager success. London: Institute of Actuaries, 1991.

van Nunen, A. Fiduciary Management: Blueprint for Pension Fund Excellence. New York: John Wiley, 2008.

Author (2002)

Author (2007)

Author (2014)

Author (2016)

Author, co-author 1 and co-author 2 (2013)

Author and co-author 2 (2017)

Author and co-author 3 (2008)

Author and co-author 3 (2010) 